\title{
EFFECT OF ADMINISTERING SODIUM CHLORATE IN DRINKING WATER ON SALMONELLA TYPHIMURIUM CONCENTRATIONS IN WEANED AND FINISHED PIGS
}

\author{
Robin C. Anderson, Todd R. Callaway, Kenneth J. Genovese, Timothy J. Anderson, \\ Thomas S. Edrington, Toni L. Poole, Kenneth M. Bischoff and David J. Nisbet
}

USDA/ARS, Southern Plains Agricultural Research Center, Food and Feed Safety Research Unit, 2881 F\&B Road, College Station, TX 77845, USA

Salmonella can cause disease and compromise food safety. Consequently, strategies are sought to reduce colonization of food animals by these pathogens. Because Salmonella, like most enterobacteria, possesses respiratory nitrate reductase activity, which coincidentally reduces chlorate to cytotoxic chlorite, we hypothesized that chlorate may selectively kill these pathogens but not beneficial gut anaerobes lacking this activity. Whereas we have since shown that oral gavage of sodium chlorate to weaned pigs does kill Salmonella in the gut, we now report results from experiments evaluating the efficacy of administering chlorate in drinking water, which is a more practical application of this technology. In our first experiment, weaned pigs orally infected with $10^{8}$ colony forming units (CFU) of a novobiocin and nalidixic acid resistant Salmonella Typhimurium were allowed ad libitum access $24 \mathrm{~h}$ later to drinking water containing either 0 ( $0 \mathrm{X}$ treatment) or $15 \mathrm{mM}$ (1X treatment) sodium chlorate. In order to promote expression of respiratory nitrate reductase activity by Salmonella and to provide at least a minimum amount of available reductant, the drinking water treatments also contained $2.5 \mathrm{mM}$ sodium nitrate and $20 \mathrm{mM}$ sodium lactate. The pigs were euthanized 24 and $36 \mathrm{~h}$ after being allowed access to the drinking water treatments and gut contents collected at necropsy were cultured quantitatively for the challenge Salmonella strain via direct plating of serial ten-fold dilutions to Brilliant Green Agar (BGA) supplemented with 25 and $20 \mu$ g novobiocin and naladixic acid $\mathrm{mL}^{-1}$, respectively. For enhanced sensitivity, the gut contents were also cultured qualitatively via initial enrichment in tetrathionate broth, further enrichment in Rappaport-Vassiliadis broth and selective differentiation on the antibiotic supplemented BGA. Incubation steps were performed at $37^{\circ} \mathrm{C}$ for 18 to $24 \mathrm{~h}$. For the pigs provided $36 \mathrm{~h}$ access to the $1 \mathrm{X}$ chlorate treatment, cecal and rectal Salmonella concentrations were reduced $(\mathrm{P}<0.05)$ compared to concentrations found in $0 \mathrm{X}$-treated pigs. For instance, mean $\pm \mathrm{SD}(n=8)$ cecal and rectal Salmonella concentrations were $3.3 \pm 2.2$ and $1.3 \pm 1.4 \log$ base $10 \mathrm{CFU} / \mathrm{g}$, respectively, in $0 \mathrm{X}$-treated pigs and were $0.6 \pm 1.1$ and $0.1 \pm 0.4 \log$ base $10 \mathrm{CFU} / \mathrm{g}$, respectively, in contents from the $1 \mathrm{X}$-treated pigs. Gut concentrations of Salmonella were also reduced ( $\mathrm{P}<0.05)$, but less so, in pigs provided $24 \mathrm{~h}$ access to water containing the $1 \mathrm{X}$ chlorate treatment. In the second experiment, similarly challenged finished pigs (6 pigs per treatment) were in this case provided ad libitum access $24 \mathrm{~h}$ post challenge to drinking water containing $0 \mathrm{X}, 1 \mathrm{X}$ or $2 \mathrm{X}$ sodium chlorate $(0,15$ or $30 \mathrm{mM}$, respectfully) plus the nitrate and lactate. For these pigs, provision of the $1 \mathrm{X}$ or $2 \mathrm{X}$ drinking water treatments for $24 \mathrm{~h}$ resulted in reductions of 2.1 and $1.4 \log$ units in cecal Salmonella concentrations, respectively, when compared to concentrations in $0 \mathrm{X}$-treated pigs $(3.8 \pm 0.7 \mathrm{log}$ base $10 \mathrm{CFU} / \mathrm{g})$. Salmonella concentrations in rectal contents from pigs provided the $1 \mathrm{X}$ and $2 \mathrm{X}$ treatments were reduced 0.6 and $1.3 \mathrm{log}$ units, respectfully, compared to concentrations found in $0 \mathrm{X}$-treated pigs $(1.9 \pm 1.6 \log$ base $10 \mathrm{CFU} / \mathrm{g})$. No effect $(\mathrm{P}>0.05)$ on water consumption $(34$ to $40 \mathrm{~mL} / \mathrm{kg}$ body wt) was observed. These results demonstrate the practicality of administering sodium chlorate as a drinking water supplement to reduce gut concentrations of Salmonella in weaned and finished pigs.

Acta vet. scand. Suppl. 98 - 2003 